\title{
Factors analysis on the use of key quality indicators for narrowing the gap of quality of care of breast cancer
}

\author{
Chao Wang, Xi Li, Shaofei Su, Xinyu Wang, Jingkun Li, Xiaoqiang Bao and Meina Liu* (1)
}

\begin{abstract}
Background: There are differences in the quality of care among breast cancer patients. Narrowing the quality differences could be achieved by increasing the utilization rate of indicators. Here we explored key indicators that can improve the quality of care and factors that may affect the use of these indicators.

Methods: A total of 3669 breast cancer patients were included in our retrospective study. We calculated patient quality-of-care composite score based on patient average method. Patients were divided into high- and low-quality groups according to the mean score. We obtained the indicators with large difference in utilization between the two groups. Multilevel logistic regression model was used to analyze the factors influencing quality of care and use of indicators.

Results: The mean composite score was 0.802 , and the number of patients in the high- and low-quality groups were 1898 and 1771, respectively. Four indicators showed a difference in utilization between the two groups of over $40 \%$. Histological grade, pathological stage, tumor size and insurance type were the factors affecting the quality of care. In single indicator evaluation, besides the above factors, age, patient income and number of comorbidities may also affect the use of these four indicators. Number of comorbidities may have opposite effects on the use of different indicators, as does pathological stage.

Conclusions: Identifying key indicators for enhancing the quality-of-care of breast cancer patients and factors that affect the indicator adherence may provide guides for enhancing the utilization rate of these indicators in clinical practice.
\end{abstract}

Keywords: Breast cancer, Comprehensive evaluation, Single indicator evaluation, Influence factor

\section{Background}

Breast cancer is one of the most common malignant tumor in women worldwide [1], and remains a major public health issue in developed and developing countries $[2,3]$. Treating breast cancer based on clinical practice guidelines can reduce the likelihood of cancer recurrence, increase survival, improve quality of life and reduce patient mortality $[4,5]$. However, a wide gap still exists between the optimal recommended care for breast cancer and actual practice [6, 7]. For example, the rates of image-guided core needle biopsy and treatment with four cycles of adjuvant chemotherapy are only 34.1 and

\footnotetext{
* Correspondence: liumeina369@163.com

Department of Biostatistics, School of Public Health, Harbin Medical University, No.157 Baojian Road, Harbin 150081, China
}

$12.1 \%$, respectively, in China $[8,9]$. A German study reported approximately $20 \%$ of patients treated with neoadjuvant therapy in the years 2009-2011 from a cohort of 39,570 patients and the treatment was recommended by the European Society of Breast Cancer Specialist (EUSOMA) [10, 11]. To ensure that actual treatment follows clinical guidelines, many institutions and professional organizations in various countries and regions have initiated great efforts to develop quality indicators for breast cancer and have applied these indicators to evaluate and monitor the quality of breast cancer care [12-15]. Quality indicators for breast cancer care can be used as a quality measurement tool for breast cancer care, and the use of these quality evaluation indicators can help identify deficiencies in the treatment process. 
In the evaluation using these quality indicators, quality of care are reflected in the performance of indicators; the more indicators are completed, the better quality of care for patients [16]. In some studies, researchers have focused on the quality indicators for which the utilization rate is lowest in the patient population [17-19]. However, the indicators may be difficult to carry out in clinical practice. For example, the implementation of breastconserving surgery is hampered by a shortage of trained radiation oncologists and technologists [8]. Instead, more attention should be paid to the indicators that the utilization rate varied largely between healthcare providers. The large rate gap indicates large room for improvement. These indicators are more likely to be key indicators with a large impact on quality of care.

The ability to successfully achieve all recommended indicators may be affected by many factors. For example, in breast-conserving therapy (BCT), which has shown increased survival rates compared with mastectomy, factors such as age, geographic location and payer status have been observed to influence the use of BCT [20]. Endocrine therapy, which may improve outcomes for breast cancer, may be affected by demographic, clinical and financial factors such as income and psychosocial factors like fear of toxicities [21, 22]. In addition, the physiological status of women at the time of breast cancer diagnosis can influence the choice for standard radiation treatment [23]. Identifying the factors that influence the application of these treatments is one of the ways to help improve the utilization rate of these indicators.

The objective of this study was to explore some indicators that can effective improve the quality of care and analyze the factors that may affect the use of these indicators. Narrowing the differences in treatment among patients may improve the overall quality of care of breast cancer patients.

\section{Methods \\ Data sources}

The process of data collection was similar to our previous study [24]. Information on patient demographics, tumor characteristics, diagnosis and treatment of breast cancer as well as data elements essential for identifying eligible patients for use of each treatment were extracted from medical records. Based on the quality of care indicators of breast cancer, a questionnaire was designed and data were collected by professionals using the questionnaire (see Additional file 1). Data were collected from medical records of patients diagnosed with invasive breast cancer in 10 tertiary hospitals, including three specialized tumor hospitals and seven general hospitals. A total of 4454 patients with primary invasive breast cancer (identified by the International classification of disease version 10 diagnosis codes: C50.902, C50.151,
C50.251, C50.351, C50.451, C50.551) received all or part of their first course treatment in treating hospitals between June 2011 and June 2013. We excluded cases with breast cancer recurrence, bilateral breast cancer and distant metastasis of advanced breast cancer and patients missing information on tumor size and other pathological information to obtain a total of 3669 cases.

\section{Quality of care indicator}

Twenty-three of the quality indicators that were previously developed by our research team were used in this study [25]. These indicators were examined throughout breast cancer care, from preoperative diagnosis to postoperative adjuvant therapy. The indicators are listed in Table 1. The denominator of the indicator denotes patients who were eligible without contraindications for the treatment, and the numerator denotes eligible patients who actually received the treatment.

\section{Study variables}

Baseline demographic information was obtained from the medical history records. Patient characteristics include age at diagnosis (<40, 40-50, 50-60, > 60 years), types of insurance (Urban Resident Basic Medical Insurance (URBMI), Urban Employed Basic Medical Insurance (UEBMI) New Rural Cooperative Medical Scheme (NCMS)), income level, comorbidity $(0,1, \geq 2)$, histological grade (high, moderately, poorly differentiated), cancer stage (I, II, III) and tumor size $(<2 \mathrm{~cm}, 2-5 \mathrm{~cm},>5 \mathrm{~cm})$. Since information on patient income could not be gathered, as an alternative, area-level annual per capita income was extracted from the statistical bulletin of the regional economy and society developed in 2012; income level was classified into lower income $(<24,565 \mathrm{RMB})$ and higher income $(\geq 24,565 \mathrm{RMB})$ groups, according to the national annual per capita income in 2012. Hospital characteristic refers to the type of hospital and included specialized tumor hospital and general hospital.

\section{Statistical methods}

We used 23 indicators in the set of quality indicators for breast cancer care. To evaluate the patients' comprehensive quality-of-care and its variation, we calculated the composite score of the patient's treatment quality based on patient average method. The score was a simple ratio of the number of indicators for which care was provided divided by the number of indicators for which care should have been provided [26]. According to the mean score of patient composite score, we divided patients into the high- and low- quality groups. Baseline characteristics of the composite score were compared with ANOVA test. Baseline characteristics across different quality groups were compared with Chi-squared test or Kruskal-Wallis $\mathrm{H}$ test depending on the type of variable. 
Table 1 Definition of quality indicators for surgical care of breast cancer

\begin{tabular}{|c|c|}
\hline Title & Quality indicators \\
\hline \multicolumn{2}{|c|}{ Process } \\
\hline 1 & Breast cancer patients who received mammography or breast ultrasound before surgery \\
\hline 2 & Breast cancer patients who had diagnosis in cytology and/or histology before surgery \\
\hline 3 & Breast cancer patients who received ER and PR assessment before systemic therapy \\
\hline 4 & HER2 assessment before systemic therapy \\
\hline 5 & Stage I-II breast cancer patients who underwent breast-conserving surgery \\
\hline 6 & Breast cancer patients who received sentinel lymph nodes biopsy \\
\hline 7 & Breast cancer patients who received axillary lymph nodes dissection \\
\hline 8 & Premenopausal breast cancer patients who were administrated adjuvant chemotherapy \\
\hline 9 & Postmenopausal breast cancer patients with high risk who received Adjuvant chemotherapy \\
\hline 10 & Breast cancer patients who were administrated at least four cycles of Adjuvant chemotherapy \\
\hline 11 & Breast cancer patients treated by trastuzumab in whom heart function was monitored every 3 months \\
\hline 12 & $\begin{array}{l}\text { Breast cancer patient whose radiotherapy treatment was completed within a 7-week interval from the initiation of radiotherapy } \\
\text { after breast-conserving surgery }\end{array}$ \\
\hline 13 & Breast cancer patients who received standard dose of radiotherapy at the whole breast after breast-conserving surgery \\
\hline 14 & Breast cancer patients who received adjuvant radiotherapy at chest wall \\
\hline 15 & Breast cancer patients who received tamoxifen or aromatase inhibitor treatment \\
\hline 16 & Breast cancer patients who received neo-adjuvant chemotherapy \\
\hline 17 & Breast cancer patients with hormone receptor status of the tumor stated in Pathology report \\
\hline 18 & Breast cancer patients with pathology report stated category of primary tumor and regional lymph nodes with histologic grade \\
\hline 19 & Breast cancer patients with pathology report stated number of Examined lymph nodes and positive nodes \\
\hline 20 & Breast cancer patients with hormone receptor status of the tumor Stated in pathology report \\
\hline 21 & Breast cancer patients with tumor size documented in pathology report \\
\hline \multicolumn{2}{|c|}{ Management of symptoms or treatment toxicity } \\
\hline 22 & Breast cancer patients who were administrated potent anti-emetic therapy \\
\hline \multicolumn{2}{|c|}{ Communication and Cooperation } \\
\hline 23 & Breast cancer patients who were recommended for five-year endocrine treatment \\
\hline
\end{tabular}

To obtain the indicator with the great degree of change of the utilization rate, we calculated the utilization rate of each quality indicator of the high- and the low- quality group and the difference of rate. The utilization rate was presented as a proportion of the sum of patients receiving care (numerator) to the total number of patients eligible for the care (denominator) [27].

Multilevel logistic regression model was used to analyze the factors that affect the use of the indicators that have great degree of change of the utilization rate. All statistical analyses were performed with SAS version 9.3 (SAS Institute, Cary, NC, USA). Statistical significance was set at $P \leq 0.05$ and all statistical tests were two-sided.

\section{Results}

Treatment quality score of breast cancer patients

Our study included a total of 3669 breast cancer patients. The mean patient score of the patient's treatment quality was 0.802 . Patients were divided into the high- quality group (1898 cases) and the low-quality group (1771 cases) according to the mean score. The mean comprehensive scores of treatment quality in the two groups were $0.89 \pm 0.06$ and $0.70 \pm 0.08$, respectively. The baseline characteristics of patients according to the score of quality of care are listed in Table 2. The differences in the comprehensive score of types of insurance, income level, number of comorbidities, histological grade, stage and tumor size were statistically significant between the two patient groups. The characteristics of patients in the low- and high-quality groups are listed in Table 2. All variables except age at diagnosis were statistically significant.

\section{Single indicator evaluation}

We constructed a radar chart (Fig. 1) to show the utilization rate of the quality of care for breast cancer in the high- and low-quality patient groups. Four indicators showed a utilization rate with a difference of over $40 \%$ 
Table 2 Comparisons of baseline characteristics between the low- and high-quality groups and the composite score among baseline categories ${ }^{a}$

\begin{tabular}{|c|c|c|c|c|c|c|}
\hline \multirow[t]{2}{*}{ Variable } & \multirow{2}{*}{$\begin{array}{l}\text { Overall } \\
N(\%)\end{array}$} & \multirow{2}{*}{$\begin{array}{l}\text { Score of } \\
\text { quality }(\bar{X} \pm S)\end{array}$} & \multirow[t]{2}{*}{$P$ value } & \multicolumn{2}{|l|}{ Quality-of-care group } & \multirow[t]{2}{*}{$P$ value } \\
\hline & & & & $\begin{array}{l}\text { Low quality }(N=1771) \\
n(\%)\end{array}$ & $\begin{array}{l}\text { High quality }(N=1898) \\
n(\%)\end{array}$ & \\
\hline Age & & & 0.1584 & & & 0.2705 \\
\hline$<40$ & $422(12.05)$ & $0.80 \pm 0.12$ & & $212(11.97)$ & $230(12.12)$ & \\
\hline $40-50$ & $1414(38.54)$ & $0.80 \pm 0.12$ & & 708 (39.98) & 706 (37.20) & \\
\hline $50-60$ & $1271(34.64)$ & $0.81 \pm 0.12$ & & $588(33.20)$ & $683(35.99)$ & \\
\hline$>60$ & $542(14.77)$ & $0.80 \pm 0.12$ & & $263(14.85)$ & $279(14.70)$ & \\
\hline Comorbidities & & & $<0.0001$ & & & $<0.0001$ \\
\hline 0 & $2934(79.97)$ & $0.80 \pm 0.12$ & & $1470(83.00)$ & $1464(77.13)$ & \\
\hline 1 & $565(15.40)$ & $0.82 \pm 0.11$ & & $235(13.27)$ & $330(17.39)$ & \\
\hline$\geq 2$ & $170(4.63)$ & $0.82 \pm 0.13$ & & $66(3.73)$ & $104(5.48)$ & \\
\hline Types of insurance & & & $<0.0001$ & & & 0.0026 \\
\hline NCMS & $1216(33.14)$ & $0.79 \pm 0.12$ & & $631(35.63)$ & $585(30.82)$ & \\
\hline URBMI & $181(4.93)$ & $0.79 \pm 0.13$ & & $94(5.31)$ & $87(4.58)$ & \\
\hline UEBMI & $2272(61.92)$ & $0.81 \pm 0.12$ & & $1046(59.06)$ & $1226(64.59)$ & \\
\hline Income & & & $<0.0001$ & & & $<0.0001$ \\
\hline$<¥ 24,565$ & $3135(85.45)$ & $0.78 \pm 0.12$ & & $1688(95.31)$ & $1447(76.24)$ & \\
\hline$\geq ¥ 24,565$ & $534(14.55)$ & $0.89 \pm 0.10$ & & $83(4.69)$ & $451(23.76)$ & \\
\hline Grade & & & $<0.0001$ & & & $<0.0001$ \\
\hline High differentiated & $185(5.04)$ & $0.81 \pm 0.11$ & & $90(5.08)$ & $95(5.01)$ & \\
\hline Moderate differentiated & $2481(67.62)$ & $0.81 \pm 0.12$ & & $1104(62.34)$ & $1377(72.55)$ & \\
\hline Poor differentiated & $558(15.21)$ & $0.80 \pm 0.12$ & & $288(16.26)$ & $270(14.23)$ & \\
\hline Unknow & $445(12.13)$ & $0.75 \pm 0.12$ & & 289 (16.32) & $156(8.22)$ & \\
\hline Stage & & & $<0.0001$ & & & $<0.0001$ \\
\hline । & $1229(33.50)$ & $0.77 \pm 0.11$ & & $753(42.52)$ & $476(25.08)$ & \\
\hline$\|$ & $1610(43.88)$ & $0.82 \pm 0.12$ & & $638(36.02)$ & $972(51.21)$ & \\
\hline III & $830(22.62)$ & $0.81 \pm 0.12$ & & $380(21.46)$ & $450(23.71)$ & \\
\hline Tumor size & & & 0.0047 & & & 0.0246 \\
\hline$<2 \mathrm{~cm}$ & $2098(57.18)$ & $0.80 \pm 0.12$ & & $1045(59.01)$ & $1053(55.48)$ & \\
\hline $2-5 \mathrm{~cm}$ & $1487(40.53)$ & $0.81 \pm 0.12$ & & $690(38.96)$ & 797 (41.99) & \\
\hline$>5 \mathrm{~cm}$ & $84(2.29)$ & $0.83 \pm 0.12$ & & $36(2.03)$ & $48(2.53)$ & \\
\hline Type of hospital & & & $<0.0001$ & & & $<0.0001$ \\
\hline General hospital & $1320(35.98)$ & $0.76 \pm 0.11$ & & $861(48.62)$ & $459(24.18)$ & \\
\hline Specialized hospital & $2349(64.02)$ & $0.82 \pm 0.12$ & & $910(51.38)$ & $1439(75.82)$ & \\
\hline
\end{tabular}

Abbreviations: NCMS New Rural Cooperative Medical Scheme, URBMI Urban Resident Basic Medical Insurance, UEBMI Urban Employed Basic Medical Insurance ${ }^{\mathrm{a}}$ Discrete variables were expressed as counts $(\%)$ and continuous variables were expressed as a mean \pm range

between the high quality and low-quality groups. Indicator 2 (breast cancer patients who had diagnosis in cytology and/or histology before surgery) showed the greatest difference $(51.72 \%)$, followed by indicator 13 (proportion of breast cancer patients who received standard dose of radiotherapy at the whole breast after breast-conserving surgery) at $43.64 \%$, indicator 15 (breast cancer patients who received tamoxifen or aromatase inhibitor treatment) at $42.84 \%$ and indicator 12 (treatment was completed within a 7-week interval from the initiation of radiotherapy after breast-conserving surgery) at $40.94 \%$.

Multilevel logistic regression analysis was performed to determine the factors that affected the quality of care, and the results are shown in Table 3 . Compared with patients 


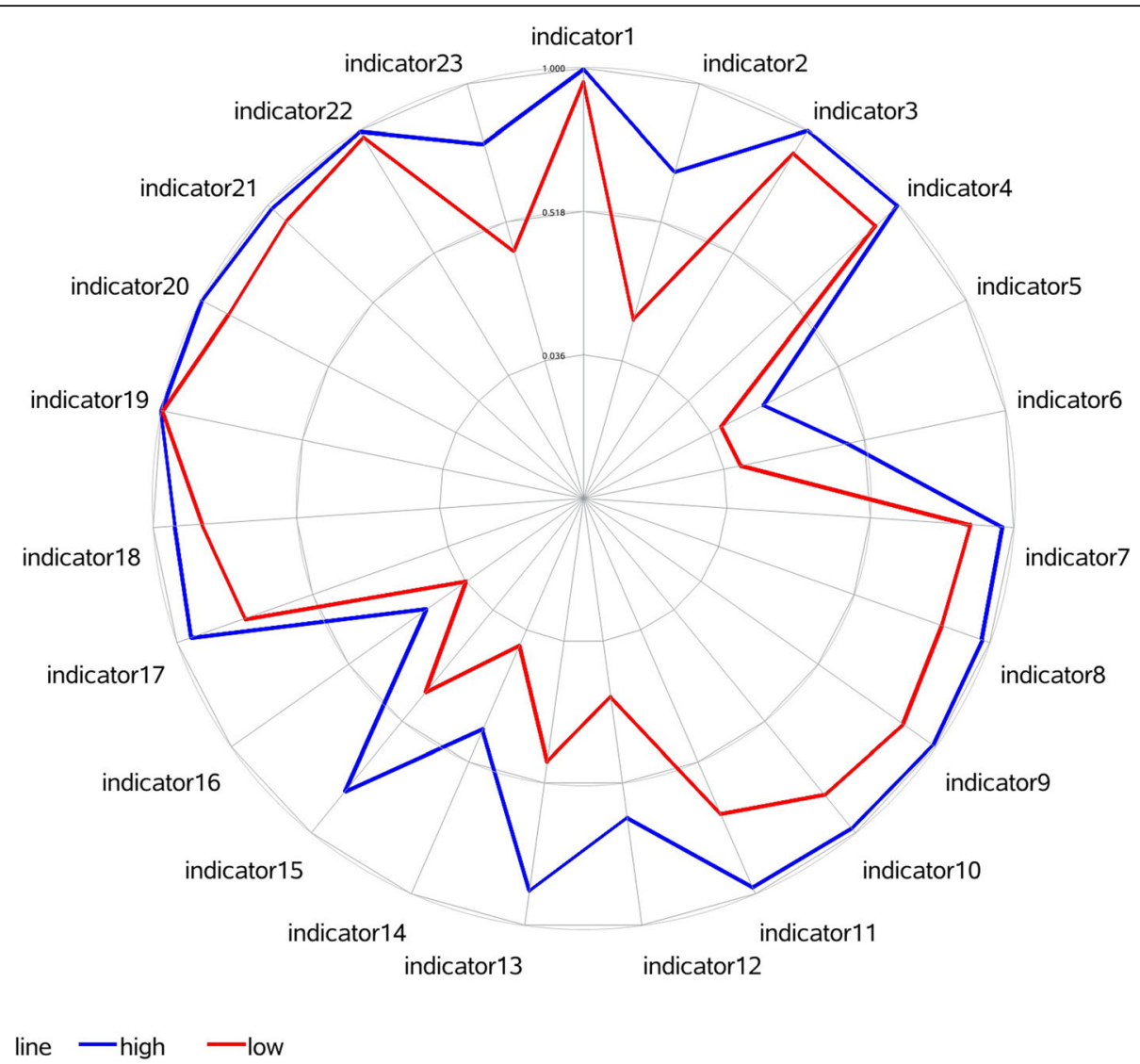

Fig. 1 Utilization rate of the quality-of-care for breast cancer in two groups by radar chart. The blue line represents the high-quality group, the red line represents the low-quality group

with stage I, high differentiated and NCMS, those whose pathological stages were stage II, stage III, histological grades were moderately and poorly differentiated, and insurances were urban insurance may be more likely to have high quality of care. Compared with patients with a tumor size $<2 \mathrm{~cm}$, patients with a tumor size of $2 \sim 5 \mathrm{~cm}$ may get low quality of care.

Multilevel logistic regression analysis was used to analyze the factors influencing whether these indicators were used and the results are shown in Table 4. Preoperative biopsy (the use of indicator 2) was more likely for patients who had more comorbidities, lower histological grade, high insurance reimbursement, large tumor size and pathologic stage II or III (all $P<0.05$ ). Patients who were younger or had pathologic stage I were more likely to receive treatment within a 7-week interval from the initiation of radiotherapy (all $P<0.05$ ). Compared with patients with pathologic stage I, patients with stage II tumors may not receive standard dose of radiotherapy at the whole breast after breastconserving surgery (all $P<0.05$ ). Complete endocrine therapy was more likely for patients who had less comorbidities, pathologic stage III and higher insurance reimbursement and income (all $P<0.05$ ).

\section{Discussion}

The quality of high- and low- quality group was obtained through comprehensive evaluation; we identified the four indicators that showed a large difference in their application between the patient groups and we analyzed the factors influencing the use of these indicators. In this study, we focused on the indicators that showed large variations in applications between high and low groups rather than indicators that were less frequently applied in both groups. The indicators which utilization rate are both low in two groups means the variations of utilization rates are little, indicated that in clinical practice they are difficult to complete among patients. In our study, the two indicators with the worst completion, in which the utilization rates were less than $20 \%$, included early stage breast cancer patients who underwent breast-conserving surgery and received neo-adjuvant chemotherapy and variation of these indicators utilization rate are both less than $15 \%$. Neoadjuvant chemotherapy and breast-conserving surgery have been a trend in breast cancer care, but these treatments require an established integrated multidisciplinary care strategy that includes pathologists, radiologists, surgeons and oncologists. Implementation of these treatments is 
Table 3 Factors that affect the quality of care in Multilevel logistic regression model ${ }^{\mathrm{a}}$

\begin{tabular}{|c|c|c|}
\hline Variables & $\mathrm{OR}^{\mathrm{a}}(95 \% \mathrm{Cl})$ & $P$ value \\
\hline \multicolumn{3}{|l|}{ Age } \\
\hline $40-50$ & $0.933(0.715-1.216)$ & 0.5939 \\
\hline $50-60$ & $1.152(0.876-1.513)$ & 0.2969 \\
\hline$>60$ & $1.202(0.864-1.672)$ & 0.2617 \\
\hline$<40$ & Ref. & \\
\hline \multicolumn{3}{|l|}{ Complications } \\
\hline 1 & $1.162(0.913-1.480)$ & 0.2058 \\
\hline$\geq 2$ & $1.272(0.833-1.942)$ & 0.2463 \\
\hline 0 & Ref. & \\
\hline \multicolumn{3}{|l|}{ Types of insurance } \\
\hline URBMI & $0.924(0.608-1.405)$ & 0.6943 \\
\hline UEBMI & $1.352(1.125-1.625)$ & 0.0032 \\
\hline NCMS & Ref. & \\
\hline \multicolumn{3}{|l|}{ Income } \\
\hline$\geq ¥ 24,565$ & $9.382(0.973-90.467)$ & 0.0521 \\
\hline$<¥ 24,565$ & Ref. & \\
\hline \multicolumn{3}{|l|}{ Grade } \\
\hline Moderate differentiated & $1.661(1.127-2.448)$ & 0.0126 \\
\hline Poor differentiated & $1.621(1.039-2.528)$ & 0.0347 \\
\hline Unkown & $0.635(0.409-0.985)$ & 0.0432 \\
\hline high differentiated & Ref. & \\
\hline \multicolumn{3}{|l|}{ Stage } \\
\hline$\|$ & $5.100(3.995-6.512)$ & $<0.0001$ \\
\hline III & $3.866(2.956-5.058)$ & $<0.0001$ \\
\hline । & Ref. & \\
\hline \multicolumn{3}{|l|}{ Tumor size } \\
\hline $2 \sim 5 \mathrm{~cm}$ & $0.487(0.392-0.607)$ & $<0.0001$ \\
\hline$>5 \mathrm{~cm}$ & $0.846(0.476-1.501)$ & 0.5447 \\
\hline$<2 \mathrm{~cm}$ & Ref. & \\
\hline \multicolumn{3}{|l|}{ Type of hospital } \\
\hline Specialized hospital & $2.901(0.396-21.233)$ & 0.2383 \\
\hline General hospital & Ref. & \\
\hline
\end{tabular}

All variables in the Multilevel logistic regression analysis were adjusted for each other a Abbreviations: OR odds ratio, NCMS New Rural Cooperative Medical Scheme, URBMI Urban Resident Basic Medical Insurance, UEBMI Urban Employed Basic Medical Insurance

also hampered by a shortage of trained medical staff [8], and thus even if we want to improve the utilization rate of indicators, it may be difficult to substantial increase their use. We calculated the utilization rate of the two indicators for each year from 2011 to 2013. The utilization rates of both indicators were very low in the 3 years and there was no obvious trend over time. The rates of breastconserving surgery from 2011 to 2013 were 13.71, 13.42, $13.58 \%$ respectively. And the rates of neo-adjuvant chemotherapy from 2011 to 2013 were 11.72, 13.92, $13.68 \%$ respectively. We may conduct a further study on how to improve the indicators with low utilization rate in the future.

The four indicators selected in the current study, in which the variations of utilization rate were more than $40 \%$, may be key indicators that lead to differences in quality of care. Because the variations of utilization rate are so great, there is tremendous room for improvement in the use of these indicators and the application could be improved relatively easily. Identification of the factors that may affect the use of these indicators may provide some suggestions for clinical improvement of quality of care. If doctors strictly followed clinical guidelines, the utilization of preoperative biopsy may be improved [28, 29], which was consistent with our results. In another study, cancer survivors who reported financial problems were also more likely to report delayed medical care or foregoing medical care and prescriptions [30-32], which was consistent with our results. For patients who received radiotherapy after breast-conserving surgery, factors such as pathological stage, and age at diagnosis may affect the application of complete radiotherapy in a standard dose and treatment within a 7-week interval.

In our study, the same factor may have opposite impacts on the use of different indicators. For patients with a relatively late pathological stage, it is more possible to conduct preoperative biopsy to understand the disease development [33], and to conduct endocrine therapy to inhibit the growth of cancer cells [30,32]. However, our study showed that these patients are less likely to have postoperative radiotherapy after breast-conserving surgery. Similarly, for patients with more comorbidities of basic diseases, doctors are more inclined to perform preoperative biopsy to choose a better treatment plan for subsequent treatment [29]. However, the side effects of endocrine treatment will aggravate patient conditions with other more basic diseases, and the treatment is difficult for most patients to endure, which will make it difficult for patients to complete endocrine treatment [34-36]. Therefore, in cases in which there are contradictions with use of indicators, it is important for doctors to weigh the advantages and disadvantages and try to select and achieve the indicators that are most suitable for patients.

This study had several limitations. First, when analyzing the single indicator influencing factors, there were no pathological stage I patients take mastectomy, we take stage II as a reference; because of the sample is a little small, for radiotherapy after BCT, fewer patients' tumor are greater than $5 \mathrm{~cm}$ and therefore we divided tumor sizes into $<2 \mathrm{~cm}$ and $\geq 2 \mathrm{~cm}$. Second, we conducted observational research and therefore we cannot prove causation between the use of indicators and characteristics of patients. Third, we didn't collect information of the reasons 
Table 4 Factors that affect the use of four indicators in Multilevel logistic regression model ${ }^{\mathrm{a}}$

\begin{tabular}{|c|c|c|c|c|}
\hline \multirow[t]{2}{*}{ Variables } & Indicator 2 & Indicator12 & Indicator13 & indicator 15 \\
\hline & $\mathrm{OR}(95 \% \mathrm{Cl})$ & $\mathrm{OR}(95 \% \mathrm{Cl})$ & $\mathrm{OR}(95 \% \mathrm{Cl})$ & $\mathrm{OR}(95 \% \mathrm{Cl})$ \\
\hline \multicolumn{5}{|l|}{ Age } \\
\hline $40-50$ & $0.807(0.608-1.071)$ & $0.468(0.125-1.753)$ & $0.862(0.325-2.282)$ & $0.943(0.693-1.282)$ \\
\hline $50-60$ & $0.850(0.635-1.138)$ & $0.203(0.044-0.928)$ & $0.676(0.228-2.001)$ & 1.219 (0.882-1.684) \\
\hline$>60$ & $0.718(0.501-1.029)$ & $2.339(0.168-32.547)$ & $0.865(0.134-5.588)$ & 1.299 (0.879-1.920) \\
\hline$<40$ & Ref. & Ref. & Ref. & Ref. \\
\hline \multicolumn{5}{|l|}{ Complications } \\
\hline 1 & $1.339(1.036-1.731)$ & $1.102(0.175-6.922)$ & $1.073(0.220-5.231)$ & 1.319 (0.982-1.773) \\
\hline$\geq 2$ & 1.830 (1.166-2.874) & $0.371(0.014-9.767)$ & $0.825(0.057-12.013)$ & $0.583(0.358-0.950)$ \\
\hline 0 & Ref. & Ref. & Ref. & Ref. \\
\hline \multicolumn{5}{|l|}{ Types of insurance } \\
\hline URBMI & $1.386(0.857-2.243)$ & $1.409(0.081-24.526)$ & $4.376(0.618-30.965)$ & $1.354(0.828-2.214)$ \\
\hline UEBMI & $1.357(1.116-1.650)$ & $1.173(0.318-4.325)$ & $2.232(0.771-6.464)$ & 1.873 (1.508-2.327) \\
\hline NCMS & Ref. & Ref. & Ref. & Ref. \\
\hline \multicolumn{5}{|l|}{ Income } \\
\hline$\geq ¥ 24,565$ & $14.142(0.384-520.935)$ & $2.625(0.014-506.325)$ & $1.841(0.064-52.931)$ & $10.341(1.161-92.116)$ \\
\hline$<¥ 24,565$ & Ref. & Ref. & Ref. & Ref. \\
\hline \multicolumn{5}{|l|}{ Grade } \\
\hline Moderate differentiated & 2.079 (1.394-3.100) & $2.466(0.430-14.139)$ & $1.344(0.310-5.830)$ & 1.072 (0.709-1.619) \\
\hline Poor differentiated & $1.654(1.035-2.643)$ & $1.645(0.223-12.109)$ & $0.473(0.080-2.798)$ & $0.917(0.544-1.547)$ \\
\hline Unkown & 3.277 (2.079-5.167) & $1.462(0.303-7.058)$ & $0.876(0.168-4.578)$ & $1.406(0.854-2.316)$ \\
\hline High differentiated & Ref. & Ref. & Ref. & Ref. \\
\hline \multicolumn{5}{|l|}{ Stage } \\
\hline$\|$ & 1.341 (1.046-1.718) & $0.254(0.079-0.813)$ & $0.250(0.091-0.685)$ & 1.071 (0.818-1.402) \\
\hline III & 1.501 (1.136-1.984) & $0.286(0.041-1.996)$ & $0.213(0.035-1.308)$ & 1.426 (1.053-1.932) \\
\hline I & Ref. & Ref. & Ref. & Ref. \\
\hline \multicolumn{5}{|l|}{ Tumor size } \\
\hline $2 \sim 5 \mathrm{~cm} / \geq 2 \mathrm{~cm}$ & $1.626(1.293-2.044)$ & $0.667(0.141-3.150)$ & $1.146(0.335-3.925)$ & $1.011(0.786-1.301)$ \\
\hline$>5 \mathrm{~cm}$ & $2.805(1.403-5.606)$ & - & - & $0.606(0.270-1.360)$ \\
\hline$<2 \mathrm{~cm}$ & Ref. & Ref. & Ref. & Ref. \\
\hline \multicolumn{5}{|l|}{ Type of hospital } \\
\hline Specialized hospital & $4.726(0.195-114.334)$ & $1.035(0.010-112.506)$ & 11.045 (0.584-208.892) & $2.648(0.394-17.822)$ \\
\hline General hospital & Ref. & Ref. & Ref. & Ref. \\
\hline
\end{tabular}

Missing data were characterized as unknown

For indicator 12, indicator 13 , tumor sizes was divided into $<2 \mathrm{~cm}$ and $\geq 2 \mathrm{~cm}$; for indicator 2 and indicator 15 , tumor sizes was divided into $<2 \mathrm{~cm}, 2 \sim 5 \mathrm{~cm}$ and $\geq 5 \mathrm{~cm}$

All variables in the Multilevel logistic regression analysis were adjusted for each other

${ }^{a}$ Abbreviations: OR odds ratio, NCMS New Rural Cooperative Medical Scheme, URBMI Urban Resident Basic Medical Insurance, UEBMI Urban Employed Basic

Medical Insurance

why patient didn't receive certain therapy or diagnostics from the medical reports, which may influence the quality scores. Finally, the breast cancer patients included in this study had invasive breast cancer. The factors that may affect quality of patients and the use of indicators may not be applicable to other types of breast cancer and other cancers.

\section{Conclusions}

Here we identified key indicators which have variation of indicators utilization rate between different quality of patients could enhance the quality of care breast cancer patients. Analysis of the factors that affect the indicator adherence may provide some guides and suggestions for enhancing the utilization rate of these indicators in clinical practice. 


\section{Supplementary information}

Supplementary information accompanies this paper at https://doi.org/10. 1186/s12885-019-6334-5.

Additional file 1. Medical record questionnaire for breast cancer patients.

\section{Abbreviations}

BCT: Breast-conserving therapy; EUSOMA: European Society of Breast Cancer Specialist; NCMS: New Rural Cooperative Medical Scheme; UEBMI: Urban Employed Basic Medical Insurance; URBMI: Urban Resident Basic Medical Insurance

\section{Acknowledgments}

Not applicable.

\section{Authors' contributions}

$\mathrm{ML}$ and $\mathrm{CW}$ conceived of the study, participated in the design and coordination. CW drafted the initial manuscript. $X \mathrm{~L}, \mathrm{SS}, \mathrm{XW}, \mathrm{JL}$, and $\mathrm{XB}$ collected and analyzed the data and revised the manuscript. All authors read and approved the final manuscript.

\section{Funding}

This work was supported by National Natural Science Foundation of China [Grant Number 81573255 to Meina Liu], which participated in the design of the study and data collection.

\section{Availability of data and materials}

The data that support the findings of this study are available from ten teaching grade A tertiary hospitals located in north of China but restrictions apply to the availability of these data, which were used under license for the current study, and so are not publicly available. Data are however available from the corresponding authors upon reasonable request and with permission of those investigated hospitals.

\section{Ethics approval and consent to participate}

Institutional Research Board of Harbin Medical University approved the study and written informed consent was obtained from all individual participants included in the study.

\section{Consent for publication}

Not applicable.

\section{Competing interests}

The authors declare that they have no competing interests.

Received: 27 March 2019 Accepted: 5 November 2019

Published online: 12 November 2019

\section{References}

1. Siegelmann-Danieli N, Khandelwal V, Wood GC, Mainali R, Prichard J, Murphy $\mathrm{TJ}$, et al. Breast cancer in elderly women: outcome as affected by age, tumor features, comorbidities, and treatment approach. Clin Breast Cancer. 2006;7(1):59-66.

2. Bazargani YT, de Boer A, Schellens JH, Leufkens HG, Mantel-Teeuwisse AK. Essential medicines for breast cancer in low and middle income countries. BMC Cancer. 2015;15:591.

3. Lim G, Aina E, Cheah S, Ismail F, Ho G, Tho L, et al. Closing the global cancer divide-performance of breast cancer care services in a middle income developing country. BMC Cancer. 2014;14:212.

4. Badakhshi H, Gruen A, Sehouli J, Budach V, Boehmer D. The impact of patient compliance with adjuvant radiotherapy: a comprehensive cohort study. Cancer Med. 2013:2(5):712-7.

5. Malin J, Schuster M, Kahn K, Brook R. Quality of breast cancer care: what do we know? J Clin Oncol. 2002;20(21):4381-93.

6. Bryant J, Boyes A, Jones K, Sanson-Fisher R, Carey M, Fry R. Examining and addressing evidence-practice gaps in cancer care: a systematic review. Implement Sci. 2014;9(1):37.
7. Teng GG, Curtis JR, Saag KG. Quality health care gaps in osteoporosis: how can patients, providers, and the health system do a better job? Curr Osteoporos Rep. 2009;7(1):27-34.

8. Fan L, Strasser-Weippl K, Li J-J, Louis JS, Finkelstein DM, Yu K-D, et al. Breast cancer in China. Lancet Oncol. 2014;15(7):e279-e89.

9. X-m Y, Wang N, Ouyang T, Yang L, M-y S, Lin B-y, et al. Current status of diagnosis and treatment of primary breast cancer in Beijing, 2008. Chin J Cancer Res. 2011;23(1):38-42.

10. Vicini E, Invento A, Cuoghi M, Bafile A, Battaglia C, Biglia N, et al. Neoadjuvant systemic treatment for breast cancer in Italy: the Italian Society of Surgical Oncology (SICO) breast Oncoteam survey. Eur J Surg Oncol. 2018;44(8):1157-63.

11. Biganzoli L, Marotti L, Hart CD, Cataliotti L, Cutuli B, Kuhn T, et al. Quality indicators in breast cancer care: an update from the EUSOMA working group. Eur J Cancer. 2017:86:59-81.

12. Chung KP, Chen LJ, Chang YJ, Chang YJ, Lai MS. Application of the analytic hierarchy process in the performance measurement of colorectal cancer care for the design of a pay-for-performance program in Taiwan. Int J Qual Health Care. 2012:25(1):81-91.

13. Malin JL, Schneider EC, Epstein AM, Adams J, Emanuel EJ, Kahn KL. Results of the national initiative for cancer care quality: how can we improve the quality of cancer care in the United States? J Clin Oncol. 2006;24(4):626-34.

14. Neuss MN, Desch CE, McNiff KK, Eisenberg PD, Gesme DH, Jacobson JO, et al. A process for measuring the quality of cancer care: the quality oncology practice initiative. J Clin Oncol. 2005;23(25):6233-9.

15. Schneider EC, Malin JL, Kahn KL, Emanuel EJ, Epstein AM. Developing a system to assess the quality of cancer care: ASCO's national initiative on cancer care quality. J Clin Oncol. 2004;22(15):2985-91.

16. Campbell SM, Roland MO, Buetow SA. Defining quality of care. Soc Sci Med. 2000:51(11):1611-25.

17. Stelfox HT, Straus SE, Nathens A, Bobranska-Artiuch B. Evidence for quality indicators to evaluate adult trauma care: a systematic review. Crit Care Med. 2011;39(4):846-59.

18. Nguyen HB, Corbett SW, Steele R, Banta J, Clark RT, Hayes SR, et al. Implementation of a bundle of quality indicators for the early management of severe sepsis and septic shock is associated with decreased mortality. Crit Care Med. 2007;35(4):1105-12.

19. Freeman T. Using performance indicators to improve health care quality in the public sector: a review of the literature. Health Serv Manag Res. 2002; 15(2):126-37.

20. Hartmann-Johnsen OJ, Karesen R, Schlichting E, Nygard JF. Survival is better after breast conserving therapy than mastectomy for early stage breast cancer: a registry-based follow-up study of Norwegian women primary operated between 1998 and 2008. Ann Surg Oncol. 2015;22(12):3836-45.

21. Hershman DL, Kushi LH, Hillyer GC, Coromilas E, Buono D, Lamerato L, et al. Psychosocial factors related to non-persistence with adjuvant endocrine therapy among women with breast cancer: the Breast Cancer Quality of Care Study (BQUAL). Breast Cancer Res Treat. 2016;157(1):133-43.

22. Hershman DL, Tsui J, Wright JD, Coromilas EJ, Tsai WY, Neugut Al. Household net worth, racial disparities, and hormonal therapy adherence among women with early-stage breast cancer. J Clin Oncol. 2015;33(9):1053-9.

23. Ballard-Barbash R, Potosky AL, Harlan LC, Nayfield SG, Kessler LG. Factors associated with surgical and radiation therapy for early stage breast cancer in older women. J Natl Cancer Inst. 1996;88(11):716-26.

24. Bao $H$, Yang F, Su S, Wang $X$, Zhang $M$, Xiao $Y$, et al. Evaluating the effect of clinical care pathways on quality of cancer care: analysis of breast, colon and rectal cancer pathways. J Cancer Res Clin Oncol. 2016;142(5):1079-89.

25. Bao H, Yang F, Wang X, Su S, Liu D, Fu R, et al. Developing a set of quality indicators for breast cancer care in China. Int J Qual Health Care. 2015:27(4): 291-6.

26. Campbell SM, Roland MO, Middleton E, Reeves D. Improvements in quality of clinical care in English general practice 1998-2003: longitudinal observational study. Bmj. 2005:331(7525):1121.

27. Li X, Zhou Q, Wang X, Su S, Zhang M, Jiang H, et al. The effect of low insurance reimbursement on quality of care for non-small cell lung cancer in China: a comprehensive study covering diagnosis, treatment, and outcomes. BMC Cancer. 2018;18(1):683.

28. Liikanen ل, Leidenius $M$, Joensuu H, Vironen J, Heikkilä P, Meretoja T, Breast cancer prognosis and isolated tumor cell findings in axillary lymph nodes after core needle biopsy and fine needle aspiration cytology. Eur J Surg Oncol. 2016;42(1):64-70. 
29. Criscitiello C, André F, Thompson A M, De Laurentiis M, Esposito A, Gelao L, et al. Biopsy confirmation of metastatic sites in breast cancer patients: clinical impact and future perspectives. Breast Cancer Res. 2014;16(2):205.

30. Hershman DL, Shao T, Kushi LH, Buono D, Tsai WY, Fehrenbacher L, et al. Early discontinuation and non-adherence to adjuvant hormonal therapy are associated with increased mortality in women with breast cancer. Breast Cancer Res Treat. 2011;126(2):529-37.

31. Henry NL, Azzouz F, Desta Z, Li L, Nguyen AT, Lemler S, et al. Predictors of aromatase inhibitor discontinuation as a result of treatment-emergent symptoms in early-stage breast cancer. J Clin Oncol. 2012;30(9):936-42.

32. Hershman DL, Kushi LH, Shao T, Buono D, Kershenbaum A, Tsai WY, et al. Early discontinuation and nonadherence to adjuvant hormonal therapy in a cohort of 8,769 early-stage breast cancer patients. J Clin Oncol. 2010;28(27): $4120-8$.

33. Meattini I, Giannotti E, Abdulcadir D, Saieva C, Guerrieri AM, Vanzi E, et al. The impact of method of biopsy on the incidence of breast cancer sentinel lymph node metastases. Eur J Surg Oncol. 2014;40(3):277-81.

34. Monnier A. Clinical management of adverse events in adjuvant therapy for hormone-responsive early breast cancer. Ann Oncol. 2007;18(Suppl 8):viii36-44.

35. Cella D, Fallowfield $\sqcup$. Recognition and management of treatment-related side effects for breast cancer patients receiving adjuvant endocrine therapy. Breast Cancer Res Treat. 2008;107(2):167-80.

36. Güth U, Myrick ME, Schötzau A, Kilic N, Schmid SM. Drug switch because of treatment-related adverse side effects in endocrine adjuvant breast cancer therapy: how often and how often does it work? Breast Cancer Res Treat. 2011;192(3):799-807

\section{Publisher's Note}

Springer Nature remains neutral with regard to jurisdictional claims in published maps and institutional affiliations.

Ready to submit your research? Choose BMC and benefit from:

- fast, convenient online submission

- thorough peer review by experienced researchers in your field

- rapid publication on acceptance

- support for research data, including large and complex data types

- gold Open Access which fosters wider collaboration and increased citations

- maximum visibility for your research: over $100 \mathrm{M}$ website views per year

At $\mathrm{BMC}$, research is always in progress.

Learn more biomedcentral.com/submissions 